\title{
(息)
}

Citation:

Simpson, J and Ali Nasir, M (2018) Brexit Associated Sharp Depreciation and Implications for UK's Inflation and Balance of Payments. Journal of Economic Studies, 45 (2). pp. 231-246. ISSN 0144-3585 DOI: https://doi.org/10.1108/JES-02-2017-0051

Link to Leeds Beckett Repository record:

https://eprints.leedsbeckett.ac.uk/id/eprint/3938/

Document Version:

Article (Accepted Version)

Creative Commons: Attribution-Noncommercial 4.0

The aim of the Leeds Beckett Repository is to provide open access to our research, as required by funder policies and permitted by publishers and copyright law.

The Leeds Beckett repository holds a wide range of publications, each of which has been checked for copyright and the relevant embargo period has been applied by the Research Services team.

We operate on a standard take-down policy. If you are the author or publisher of an output and you would like it removed from the repository, please contact us and we will investigate on a case-by-case basis.

Each thesis in the repository has been cleared where necessary by the author for third party copyright. If you would like a thesis to be removed from the repository or believe there is an issue with copyright, please contact us on openaccess@leedsbeckett.ac.uk and we will investigate on a case-by-case basis. 


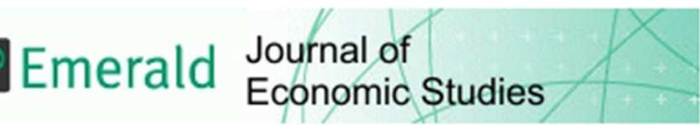

\section{Brexit Associated Sharp Depreciation and Implications for UK's Inflation and Balance of Payments}

\begin{tabular}{|r|l|}
\hline Journal: & Journal of Economic Studies \\
\hline Manuscript ID & JES-02-2017-0051.R1 \\
\hline Manuscript Type: & Research Paper \\
\hline Keywords: & $\begin{array}{l}\text { Exchange Rate, Inflation, Balance of Payment, J-Curve, Brexit, TV-SVAR } \\
\text { Model }\end{array}$ \\
\hline \multicolumn{2}{|c}{} \\
\hline
\end{tabular}




\section{Summary of Revisions}

We would like to express our deepest gratitude for anonymous referees for their kind review of our paper and very useful remarks and feedback which helped us to revisit/revise our work and led to significant improvement. The summary of the actions taken in the light of referee's remarks/feedback is as follow;

\begin{tabular}{|c|c|c|}
\hline \# & Review Remarks/Comments & Replies and Action Taken \\
\hline 1. & $\begin{array}{l}\text { The paper claims to have used advanced } \\
\text { approach - TVSVAR, for analysing the } \\
\text { implications of exchange rate depreciation } \\
\text { for inflation and trade balance of United } \\
\text { Kingdom. However, what the paper is } \\
\text { contributing to the existing literature is not } \\
\text { so motivated to be considered to the } \\
\text { journal like this. Further, mere using of } \\
\text { different methodology does not satisfy the } \\
\text { condition of contribution towards existing } \\
\text { literature until it challenges the existing } \\
\text { theory or methodology. There is no } \\
\text { methodological contribution or innovation } \\
\text { provided by the paper. The paper did not } \\
\text { provide any clear explanation, if any, on } \\
\text { the contribution to the vast existing } \\
\text { literature. The paper looks like a } \\
\text { mechanical output from a given software. }\end{array}$ & $\begin{array}{l}\text { We agree and appreciate the } \\
\text { points raised by referees, } \\
\text { considering their remarks, we } \\
\text { have highlighted and elaborated } \\
\text { the theoretical contributions this } \\
\text { study is making to the existing } \\
\text { body of knowledge and debate } \\
\text { on the nexus between the } \\
\text { underlying economic variables. } \\
\text { In this regards we have drawn } \\
\text { on the notion put forward by } \\
\text { Forbes (2015) on the issue of } \\
\text { time variation of pass-through } \\
\text { which has ben } \\
\text { underappreciated both by } \\
\text { academics and practitioners, in } \\
\text { addition to that have also } \\
\text { highlighted the implications of } \\
\text { time variation for the trade } \\
\text { balance. Furthermore, in terms } \\
\text { of philosophical underpinning, } \\
\text { we have acknowledged the idea } \\
\text { of chain reasoning discussed by } \\
\text { and Keynes (1938) critique. } \\
\text { Please refer to page } 3 \text { and Page } \\
5-6 \text { Lastly, we have also } \\
\text { elaborated on the aspect of } \\
\text { inflation targeting and its } \\
\text { implications for the Pass- } \\
\text { through. }\end{array}$ \\
\hline 2. & $\begin{array}{l}\text { The paper uses multivariate stochastic } \\
\text { model with time varying coefficients and } \\
\text { time varying variance covariance matrix. } \\
\text { Further the model has been estimated } \\
\text { with Bayesian approach where the } \\
\text { conditional posteriors are known but } \\
\text { posterior distribution is unknown. The } \\
\text { author(s) have not explained, in section } \\
3.3 \text {, how they have drawn the } \\
\text { coefficients from the posterior } \\
\text { distribution. }\end{array}$ & $\begin{array}{l}\text { Considering the remarks by } \\
\text { referee we have explain the } \\
\text { posterior sampling in section } 3.3 \text {. } \\
\text { In order to draw from the } \\
\text { posterior distribution we used the } \\
\text { Gibbs sampling, Gibbs Sampling is } \\
\text { employed for the posterior } \\
\text { numerical evaluation of the } \\
\text { parameters of interest. To start } \\
\text { with } 48 \text { observations (three years } \\
\text { data) period is chosen for a } \\
\text { training sample. Thereafter run } \\
10000 \text { iterations of Gibbs } \\
\text { Sampling with a burn rate of } 20 \% \\
\text { i.e. (2000 iterations). The burn }\end{array}$ \\
\hline
\end{tabular}


3. The author(s) has/have interpreted the estimates, rather it would have better if there was a suitable explanation provided for the estimates which related the results to the existing literature and suggests the policy recommendations for the future. I do not know how the audience will be benefited by this explanation. rate is chosen so that discarding an initial portion of a Markov chain sample so that the effect of initial values on the posterior inference is minimized. Please refer to page 8 .

Considering referees remarks we have explained in the results and elaborated the implications of our findings. in this regards we have contextualised our findings (on trade balanceexchange rate nexus) with reference to the existing literature on the subject and referred to studies e.g. Rose and Yellen (1989), Rose (1991) Aristotelous (2001) BahmaniOskooee and Ratha (2004), Bahmani-Oskooee and Kovyryalova (2008) BahmaniOskooee and Hegerty (2010), Pattichis (2012) BahmaniOskooee et al., (2013), Bahmani-Oskooee and Harvey (2015), Yildirim and Ivrendi (2016) and Bahmani-Oskooee (2016), please refer to page 11 -12 .

Similarly, we also discussed the implications of our findings on pass-through with reference to existing evidence, e.g. Bahmani-Oskooee (1991) and indicated the contribution the study makes on the notion of inflation targeting and its role in diminishing pass-through. In this regard, it contradicts the argument put forward by Gagnon and Ihrig (2004) and Edwards (2007) that the inflation targeting could have dampened the pass-through. Please refer to pages 12- 13 .

4. The paper has too ambitious of Brexit, but Considering the referee's 
has fallen short form the pure economic analysis.

5. Explanation from figures depicting Impulse response functions of underlying variables i.e. inflation or BOP can be seen in the analysis part but the variance of the process thereby has not been again highlighted.

6. Author(s) argue on page 3 , that there is also a strong evidence of $\mathrm{J}$ curve. But where is the J curve in manuscript? How the journal audience can take this statement?

7. During Post Brexit period, the graph shows rising inflation. The authors have not explained the possible reasons for this. Also it would have been interesting to see the implications of currency depreciation on BOP \& inflation separately during pre \& post Brexit event.

8. Topological errors are more often visible in the whole manuscript.

- See page 3, line 3; (Exiting) it should have been written as existing

- Line 16; (impaction) it should have been written as impact

- Line 24 (there was also strong evidence of J curve) should have been written as there was also

- strong evidence from J curve.

- Section 2, line 1 (ML) is not defined

- Line 5; (there is rather a J curve behaviour prevails) should have written as there is rather a J

- curve that prevails.

- Line 13 (Statically) its statistically

9. Some citations that appear in the text are not backed by their corresponding references e.g. Pattichis (2012), yieldirim \& Ivrendi(2016); Gerlash(1993); Balcilar et al (2016); Sargent (2003); Hume (1742) and so on.

10. After figure 1 , it should have been figure The figure numbers have been comments we have elaborated on the economic implications beyond the Brexit, this has been done by addressing points 1-4. Furthermore, in the conclusion section the economic and policy relevance has been elaborated (Page 13).

The variance of the process, has been highlighted in the figure 3, please refer to page 10 .

The J-curve has been discussed and elaborated, please refer to page 11 . In addition to that, for the interest of readers, it has been suggested to refer to Bahmani-Oskooee and Ratha (2004) for a good insight into the literature on J-curve.

The differences among the periods have been highlighted and explicitly discussed. Please refer to pages $11 \& 13$,.

We appreciate the referees for identifying these errors. All the typing errors indicated by referees have been rectified and a proof reading has been performed to address spelling and grammatical mistakes.

The citations and references have been checked and corrections have been made. 
1

2

3

4

5

6

7

8

9

10

11

12

13

14

15

16

17

18

19

20

21

22

23

24

25

26

27

28

29

30

31

32

33

34

35

36

37

38

39

40

41

42

43

44

45

46

47

48

49

50

51

52

53

54

55

56

57

58

59

60
2. But it's figure $3 \&$ thus making things corrected. We are thankful to ambiguous. errors. 


\title{
Brexit Associated Sharp Depreciation and Implications for UK's Inflation and Balance
} of Payments

\begin{abstract}
This study has analysed the implications of exchange rate depreciation for inflation and the trade balance of the United Kingdom in the context of Brexit. Employing a TVSVAR framework in which the sources of time variation were both the coefficients and variancecovariance matrix of the innovations on the data from Jan 1989 to Sep 2016, we found that the sharp depreciation of Stirling led to significant improvements in the external balance as well as steering inflation towards the target. The empirical evidence does not support the notion that the inflation targeting could lead to diminishing pass-through; in fact, there has been an increase in the responsiveness of inflation and trade balance to real exchange rate shocks. The findings have profound implications for the British economy in the Post-Brexit epoch.
\end{abstract}

Key Words: Exchange Rate, Inflation, Balance of Payment, J-Curve, Brexit, TV-SVAR Model

JEL Codes: E31, F31, F32 


\section{Introduction:}

Brexit is one of the most significant events of recent political and economic history with implications for the European Union and the British economy in particular ${ }^{1}$. The outcome of the referendum was to leave the EU, which led to a wave of uncertainty in the economic and financial world and among other reactions; the British Pound incurred one of the sharpest deprecations in its history. Against the US $\$$ the GBP $£$ depreciated to its lowest level in 31 years and moved to $£ 1=\$ 1.21$. Concomitantly, among others factors, this sharp depreciation could have profound implications for the British economy and the financial sector which by any measure are nontrivial in terms of their size and significance. The British economy is the fifth largest economy in the world and its financial sector is top of the list in the Global Financial Centre Index (GFCI, 2016).

A bird's eye view of the macroeconomic outlook of the British economy in recent history makes two factors prominent which are also the focus of this study. These are the low level of inflation and huge current account deficit. Inflation has been persistently low for a number of years but particularly in the last two years, it has been below the $2 \%$ rate which is the statutory target given to the Bank of England.

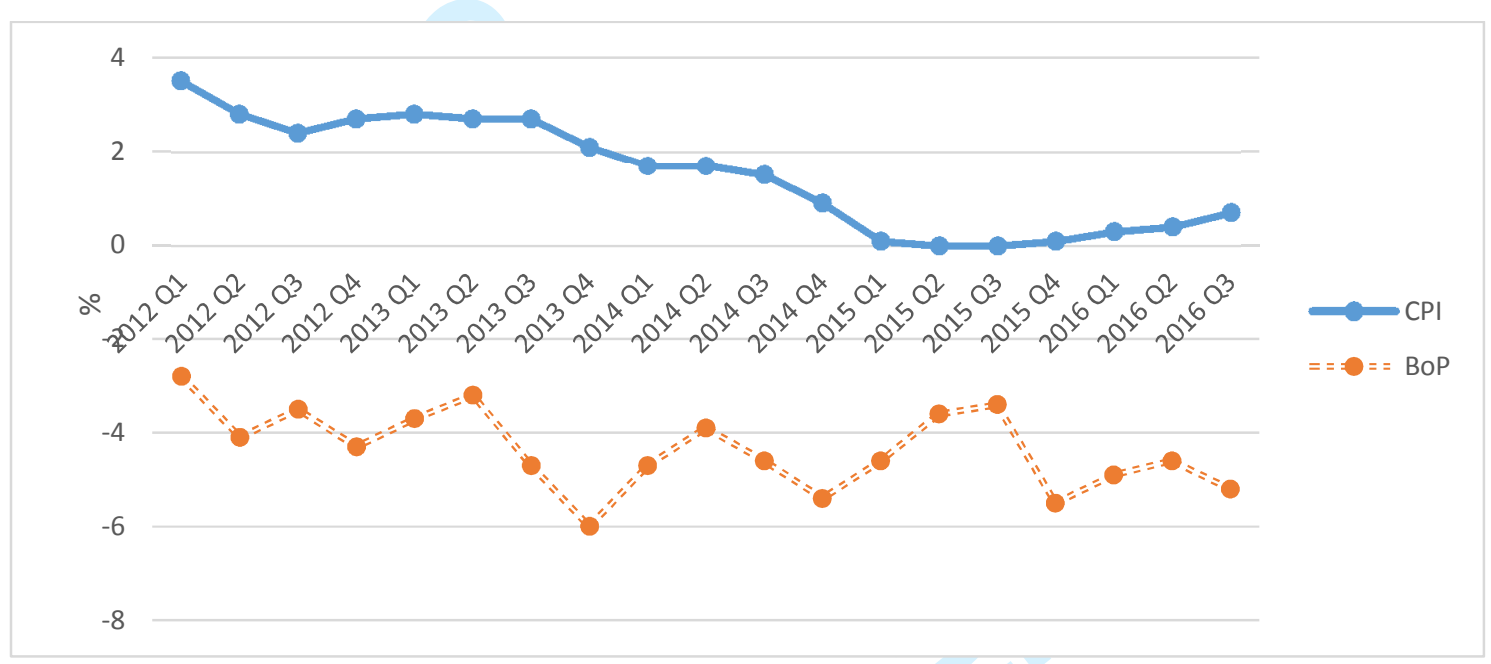

Figure 1: CPI \& Balance of Payment (C/A as \% GDP): Source (Office for National Statistics: ONS)

In the external balance, Britain has also been running one of the largest trade deficits where its trade deficit reached the highest in history. The United Kingdom's current account deficit was over $£ 25$ billion in the $3^{\text {rd }}$ Quarter of 2016 , equating to $5.2 \%$ of gross domestic product (GDP) at current market prices, the largest proportion since quarterly records began in 1955 , up from $6 \%$ in the 4th quarter of 2013 (Office for National Statistics (ONS), 2016.

Despite the bleak scenario presented above of lower than target inflation and a high current account deficit, the depreciation of the GBP $(\mathfrak{E})$ has a silver lining. Theoretically, the depreciation of a currency can have a positive impact on inflation (Pass-through) as well as the trade balance. On this notion, one can go back as far as Hume's ('1742) price-specie flow mechanism argument ${ }^{2}$. However,

\footnotetext{
${ }^{1}$ In response to the referendum British voters, choose to leave the European Union.

${ }^{2}$ Hume (1742) while arguing in favour of free trade made the case against the mercantilist idea of having policy to run a favourable or positive trade Balance. The price-specie flow mechanism states that, countries with positive trade balances are effectively importing gold (money) in exchange for their exports while those with negative trade balances are exporting gold in exchange for imports. The increase in gold in countries with positive trade balances causes inflation, which makes prices rise and in turn makes imports more competitive. Conversely, the decrease in gold in countries with negative trade balances causes deflation, which makes prices fall and exports more competitive internationally. This causes the balance of trade to shift in both countries.
} 
the net benefit of depreciation can only be positive if the elasticities of exports and imports sum up to a value greater than unity i.e. the Marshall- Learner condition (See Bahmani-Oskooee Ratha, 2004 for interesting insight). The existing evidence on the subject suggests that there can be considerable improvements made in the external balance of both developed and developing countries (see Bahmani-Oskooee, 1991; Bahmani-Oskooee and Ratha, 2004; Bahmani-Oskooee and Hegerty, 2010; Bahmani-Oskooee et al., 2013, Bahmani-Oskooee,2016; Yildirim and Ivrendi, 2016, discussed further in the next section). However, there are also some studies which failed to find significant evidence of exchange rate movements on the balance of payment, for instance, Rose and Yellen (1989) and/or Rose (1991). This study adds to the debate by analysing the implications of the exchange rate for the UK balance of trade which is running the largest deficit in the context of Brexit associated sharp depreciation. Secondly, we are also investigating the implication of exchange rate depreciation for inflation which has been below even the modest target of $2 \%$, posing a risk of deflation. On this aspect, there are some remarkable studies, for instance, Bahmani-Oskooee (1991), Wimanda (2014) and Yildirim and Ivrendi (2016) which reported a positive impact of exchange rate depreciation on inflation (detailed discussion in next section). An important contribution this study is endeavouring to make to the debate on the exchange rate and inflation nexus is by considering the time-variant aspect of this relationship. On this Issue Forbes (2015) argued that "One assumption that is traditionally made in many institutions when analysing pass-through is that it is fairly stable over time - at least within a given country. This assumption has continued to be used in most analyses of pass-through, despite it being challenged in a number of studies over the years - including at the Bank of England (Forbes Page 14)". Concomitantly, we are considering the time-varying association between the exchange rate and inflation, nevertheless, we are also including the balance of trade into the analysis as the relationship between the exchange rate and trade balance may also vary over time. The underlying logic of that could be the increasing cross-border trade and economic integration which varies over time. Lastly, the UK is an economy where inflation has been explicitly targeted for the last 25 years $^{3}$, on this aspect, there is a notion that the inflation targeting could diminish the impact of the exchange rate on inflation (See, Edwards (2007). In this study, we will put this notion to the empirical testing and see if the importance of exchange rates for inflation have diminished due to inflation targeting.

Putting all the aspects together, specifically, in this study, we analysed the impact of real effective exchange rates for inflation and the balance of payments of the British economy in a time varying setting. In order to do so, we employed a Time-Varying Structural Vector Auto-regression Model (TVSVAR hereafter) in which the sources of time variation were both the coefficients and variancecovariance matrix of the innovations on the data from Jan 1989 to Sep 2016. The key findings suggest that the sharp depreciation of Stirling is associated with the surge in inflation, which could help to bring inflation back to its target in a regime where it has been persistently low. Despite, the inflation targeting, there is strong evidence of pass-through. The depreciation of Stirling also leads to considerable gains in the external balance as it can also help to bring considerable improvements in the balance of payments. There was also strong evidence from the J-curve. Looking forward, any fruits which the exchange rate adjustments may bring in the future will be contingent on the outcome of the Brexit negotiations and future trading relationships of the UK.

The paper proceeds as follows, Section 2 provides a discussion on the nexus between exchange rates, inflation and Trade Balance, Section 3 briefly describes the layout of the empirical framework,

Thus, Hume argued that a trade balance is relatively unimportant because it tends to balance itself out in the long term.

${ }^{3}$ The United Kingdom was the second country which started inflation targeting in 1992, proceeded by New Zealand which pioneered the strategy of inflation targeting in 1990 (See Haldane, 1995 for detailed insight and discussion on inflation targeting). 
Section 4 will present the findings and Section 5 will draw conclusions and discuss the policy implications.

\section{Depreciation, Prices and Balance of Trade}

Contingent on Marshall-Learner condition ${ }^{4}$, exchange rate depreciation can lead to improvements in the balance of trade due to an increase in exports or decrease in imports. However, the improvement in the trade balance does not very often instantaneously follow depreciation. Seminal work by Bahmani-Oskooee and Ratha (2004), Bahmani-Oskooee and Hegerty (2010) and Bahmani-Oskooee et al., (2013) have shown that there is a J-curve that prevails. Depreciation initially harbours deterioration and thereafter an improvement in the trade balance. The depreciation and resulting improvement can also be through expenditure switching and expenditure changing policies (Yildirim and Ivrendi, 2016). On the other hand, analysing the impact of exchange rate depreciation on a number of developing countries Rose (1990) argued that the depreciation of the real exchange rate is not strongly associated with a significant improvement in the trade balance. Similarly, Rose and Yellen (1989) failed to find the persistent evidence of the J-curve in the US data. Rose (1991) analysing the Post-Breton Woods period (1974 - 86) data of five OECD (UK, Canada, US, Germany, Japan) countries argued that there is not statistically significant evidence of exchange rate affecting the trade balance. However, an important point we would like to emphasise here is that these studies were mostly done in the context of the US, furthermore, since then, there has been a boom of globalisation and international economic integration has been increased. Particularly the economy in question is the British economy which is one of the most open economies in the world with trade equating $62 \%$ of $\mathrm{GDP}^{5}$. Nevertheless, there is evidence of heterogeneity in the way each economy responds to the exchange rate shocks, for instance, a study Boyd et al (2001) while analysing the data of the eight OECD countries (including the UK) ${ }^{6}$ reported a heterogeneous response of economies to exchange rate shocks. Furthermore, their analysis showed that over all the exchange rate depreciation can lead to improvement in the balance payment as they observed the presence of J-curve which concomitantly led them to argue that the ML condition holds in the long-run. Similarly, in the seminal work on the LDCs, Bahmani-Oskooee (1991) found that the in the long run devaluation improves the trade balance of most of countries, whereas, a study by Lane et al (2002) found a negative impact of exchange rates (appreciation) on the trade balance in developed countries. Although, in specific to UK Aristotelous (2001) analysis spanning a century (1899-1999) showed that neither exchange-rate volatility nor the different exchange-rate regimes have significantly affected the UK export volume to the US, their approach was limited to a UK-US trade relationship. This study differs in a way that it is not looking at just exports but the balance of trade and not only to the US but with rest of the world. Perhaps, focusing on bilateral trade relationships may not provide the snapshot of a wider horizon. For instance, Chiu et al (2010) found that exchange rate depreciation could deteriorate the US balance of trade with 13 trading partners but at the same time, it leads to a balance of trade improvement with 37 of its trading partners. Further, a study by Bahmani-Oskooee and Kovyryalova (2008) focusing on US-UK trade, showed that the real exchange rate has a short-run effect on the trade balance in the majority of industries considered. Their analysis has provided support for the J-curve effect. Similar findings were reported by Pattichis (2012) while analysing the implications of exchange rate depreciation on trade in services between US-UK. The results revealed that the real exchange rate has a statistically significant effect on trade in services. They also reported the evidence of the J-curve effect. A recent study by Bahmani-Oskooee (2016) reported a significant impact of the UK exchange rate dynamic for British trade balance with eight of its trading partners (Germany, US, Canada, Italy,

\footnotetext{
${ }^{4}$ The net benefit of depreciation can only be positive if the elasticities of export and import sum up to a value greater than unity i.e. Marshall- Learner condition (Bahmani-Oskooee Ratha, 2004)

5 Exports and imports of goods and services individually accounted for around 30\% and $32 \%$ of GDP respectively in UK. (ONS, 2016)

${ }^{6}$ Canada, France, Germany, Italy, Japan, Netherlands, UK and US
} 
Japan, Korea, Spain and Norway). They reported asymmetries in the impact as well as duration. On the recent evidence from developing countries, Yildirim and Ivrendi (2016), showed that the exchange rate depreciation typically generates a deep recession and high inflation while improving the trade balance in the four emerging economies (Brazil, Turkey, Russia, and South Africa). Further evidence on developing countries, Aftab et al (2016) reported the significant impact of exchange rate volatility in the trade flows in Malaysia and Thailand.

On the impact of exchange rates on inflation, Bahmani-Oskooee (1991) established that the current floating exchange rate system, exchange rate variability is another factor contributing to inflation variability. A comprehensive empirical analysis was conducted in their study using cross-country data from 20 developed and 76 less developed countries. In later studies, Ali, and Anwar (2016) report significant effects on prices, especially input imports. There are a number of countries which explicitly target inflation in specific to the UK at $2 \%$ of CPI annually. The significance of an inflation target is that unlike monetary targeting, it does not depend on the stability of the demand for money and, unlike foreign exchange targeting, does not require changes in interest rates, direct foreign exchange intervention, and the loss of independent monetary policy (see Mishkin, 1998; Canarella and Miller 2016). On the aspect of inflation targeting, a study by Gerlach (1994) argued that there is a symmetry implying the importance of exchange rates in this regard. Although, Pourroy (2012) argued that a managed exchange rate environment delivers a stronger nominal anchor to inflation shock and concomitantly helps in the inflation targeting, in specific to the UK the exchange rate is not managed but inflation has a statutory target, hence depreciation has implications for price stability. On the idea of a flexible exchange rate, Ghosh et al (2013) showed that flexible exchange rates could be more effective in the external balance adjustment ${ }^{7}$. Perhaps, on this aspect in the UK, we are not faced with the "fear of floating" highlighted by Calvo and Reinhart (2000), as there is a free float. Interestingly, although Calvo and Reinhart (2000) argued that the pass through of inflation from exchange rate swings is larger in the emerging markets as compared to developed countries, there was a strong opposition to exchange rate pegging put forward by Mishkin (1998). The question of managed or float is beyond the scope of this study, yet in the given exchange rate regime and inflation targeting regime, the question is what implications depreciation can have for inflation in the UK. A Study by Edwards (2007) while investigating the relationship between inflation and exchange rate targeting argued that the countries that have adopted inflation targeting have experienced a decline in the pass-through from exchange rate changes to inflation. Moreover, the adoption of inflation targeting monetary policy procedures have not resulted in an increase in the volatility of exchange rates. Similarly, Gagnon and Ihrig (2004) on developed countries argued that the pass through in developed economies has declined due to inflation targeting. The subject study will give us further insight into what implications it could have for the UK where we have an explicit and statutory inflation-targeting framework. Does the exchange rate depreciation still have some implications for inflation and specifically in the context of the Brexit saga? In particular, we are employing a time-varying framework that will cater for the time variation aspect, covering the period of the UK moving to inflation targeting as well as the events of Brexit. On the choice of framework, Balcilar et al (2016) urged the use of the Time-Varying parameter model while analysing the impact of supply and demand shocks to the exchange rate, although in our case the line of reasoning and direction of causality is rather from exchange rates to inflation and trade balance, yet the time-varying framework is appropriate to give us an insight into the under analysis axioms which can hold against time variation. The rationale of considering the time-contingent association of economic entities is manifested in the reasoning of Keynes (1938) as:-

"[E]conomics is a science of thinking in terms of models joined to the art of choosing models which are relevant to the contemporary world. It is compelled to be this, because, unlike the typical natural

\footnotetext{
${ }^{7}$ They also used trade-weighted bilateral exchange rate volatility measures, in this study our exchange rate measure i.e. the Real Effective Exchange Rate is also a trade-weighted measure.
} 
science, the material to which it is applied is, in too many respects, not homogeneous through time. The object of a model is to segregate the semi-permanent or relatively constant factors from those which are transitory or fluctuating so as to develop a logical way of thinking about the latter, and of understanding the time sequences to which they give rise in particular cases".

Concomitantly, acknowledging the weaknesses of axioms in the face of tides of time, we are employing a time-variant framework. The next section will elaborate it further.

\section{Methodology}

In order to analyse the impact of real effective exchange rates on the balance of payments and inflation in the UK, we are considering a Time-Varying Structural Vector Autoregressive (TVSVAR) model which is based on the seminal work by Primiceri ${ }^{8}$ (2005). The beauty of this framework is that both the coefficients and the entire variance-covariance matrix of the shocks are allowed to vary over time. This is crucial if the objective is distinguishing between changes in the typical size of the exogenous innovations and changes in the transmission mechanism of exchange rate shocks (Primiceri, 2005). It is suitable to capture changes in private sector behaviour, where aggregation among agents usually plays the role of smoothing most of the changes. Specifically, the existence of any type of learning dynamics in terms of association among under analysis entities (exchange rates, the balance of trade and inflation) seems to favour a model with smooth and continuous drifting coefficients and heteroscedasticity innovations.

\subsection{The Model}

The TVSVAR model employed in this study has properties of both time varying coefficients and a time-varying variance-covariance matrix of the additive innovations. It is useful in the sense that drifting coefficients capture possible nonlinearities or temporal variation in the lag structure of the model. Nevertheless, the multivariate stochastic volatility captures the possible heteroscedasticity of the shocks and nonlinearities in the simultaneous relations among the variables of the model. Given that the time variation is allowed both in the coefficients and the variance-covariance matrix, leaves it up to the data to determine whether the time variation of the linear structure derives from changes in the size of the shocks (impulse) or from changes in the propagation mechanism (response). A point to be noted here is that the TVSVAR framework admits many types of shocks (for details see Cogley and Sargent 2003, and Primiceri, 2005). Let's consider the following model:-

$$
y_{t}=C_{t}+B_{1, t} y_{t-1}+\ldots \ldots \ldots+B_{k, t-k}+u_{t} \quad \mathrm{t}=1, \ldots \ldots \ldots, \mathrm{T} .
$$

Where $y_{t}$ is an $\mathrm{n} \times 1$ vector of observed endogenous variables; specific to this study, these will be exchange rates, inflation and the current account balance; $C_{t}$ is an $\mathrm{n} \times 1$ vector of time varying coefficients that multiply constant terms; $B_{i, t, i=1, \ldots, k}$ are the $\mathrm{n} \times \mathrm{n}$ matrices of time varying coefficients; $u_{t}$ are heteroscedastic unobservable shocks with variance covariance matix $\Omega_{t}$ defined by

$$
A_{t} \Omega_{t} A_{t}^{\prime}=\sum_{t} \sum_{t}^{\prime}
$$

Where $A_{t}$ is the lower triangular matrix,

$$
A_{t}=\left[\begin{array}{cccc}
1 & 0 & \ldots & 0 \\
a_{10} & 1 & \ddots & \vdots \\
\vdots & \ddots & \ddots & 0 \\
a_{n 1, t} & \ldots & a_{n n-1, t} & 1
\end{array}\right]
$$

\footnotetext{
${ }^{8}$ Please see Primiceri (2005) for an interesting insight into the development of the TVSVAR framework.
} 
And $\sum_{t}$ is the diagonal matrix

$$
\sum_{t}=\left[\begin{array}{cccc}
\sigma_{1, t} & 0 & \ldots & 0 \\
0 & \sigma_{2, t} & \ddots & \vdots \\
\vdots & \ddots & \ddots & 0 \\
0 & \ldots & 0 & \sigma_{n, t}
\end{array}\right]
$$

Thus, it follows that

$$
\begin{gathered}
y_{t}=C_{t}+B_{1, t} y_{t-1}+\ldots \ldots \ldots . . .+B_{k, t-k}+A_{t}^{-1} \sum_{t} \varepsilon_{t} \\
V\left(\varepsilon_{t}\right)=I_{n}
\end{gathered}
$$

Stacking in a vector $B_{t}$ all the Right hand Side coefficients in the equation (3) can be rewritten as

$$
\begin{gathered}
y_{t}=X_{t}^{\prime} B_{t}+A_{t}^{-1} \sum_{t} \varepsilon_{t}, \\
X_{t}^{\prime}=I_{n} \otimes\left[1, y_{t-1}^{\prime}, \ldots, y_{t-k}^{\prime}\right]
\end{gathered}
$$

Where the symbol $\otimes$ denotes the Kronecker product. It is common to decompose the variancecovariance matrix as occasioned in equation (4), this practice is more common in the studies focused on the problem of efficiently estimating covariance matrices (see, Smith and Kohn (2002), Primiceri, 2005). Similar decomposition is also evident by studies e.g. Cogley (2003) and Cogley and Sargent (2003) employing Time-Varying VAR models, however, with a time invariant $A_{t}$ matrix. As we have discussed earlier, it is vital to allow the matrix $A_{t}$ to vary over time for a time varying structural VAR framework. Keeping the $A_{t}$ constant would imply that an innovation to the $i-t h$ variable has a time invariant effect on the $j-t h$ variable. This is definitely undesirable if we are aiming to model the time variation in a simultaneous equation model, particularly, where simultaneous interactions among variables are fundamental as in this study ${ }^{9}$. At this juncture, if we let the $a_{t}$ be the vector of non-zero and non-one elements of the matrix $A_{t}$ and $\sigma_{t}$ be the vector of the diagonal element s of the matrix $\sum_{t}$. The dynamics of our model's time varying parameter can be specified in the following fashion:-

$$
\begin{aligned}
& B_{t}=B_{t-1}+v_{t}, \\
& a_{t}=a_{t-1}+\zeta_{t}, \\
& \log \sigma_{t}=\log \sigma_{t-1}+\eta_{t},
\end{aligned}
$$

Where the elements of the vector $B_{t}$ are modeled as random walks, as well as the free elements of the matrix $A_{t} \cdot{ }^{10}$ Although the random walk process might be considered undesirable here due to the

\footnotetext{
${ }^{9}$ The modelling strategy entails modelling the coefficient process in (4) and one to one mapping from equation 1 to 4 justifies this approach.

${ }^{10}$ The standard deviations $\sigma_{t}$ are assumed to evolve as geometric random walks and classed as stochastic volatility, this is an alternative to the ARCH models with the crucial difference that the variances generated are unobservable components. On this aspect, Shepherd (1996) provided a good overview and comparative analysis of stochastic volatility models with ARCH.
} 
general perception that it hits any upper or lower bound with probability one. However, as long as the $(5-7)$ are placed for a finite period of time this set of assumptions are innocuous. Nevertheless, the random walk assumption comes with the advantage of focusing on permanent shifts and reduced numbers of parameters (Primiceri, 2005). All the innovations in the model are assumed to be jointly normally distributed with the following assumptions on the variance covariance matrix:

$$
V=\operatorname{Var}=\left(\left[\begin{array}{c}
\varepsilon_{t} \\
v_{t} \\
\zeta_{t} \\
\eta_{t}
\end{array}\right]\right)=\left[\begin{array}{cccc}
I_{n} & 0 & 0 & 0 \\
0 & Q & 0 & 0 \\
0 & 0 & S & 0 \\
0 & 0 & 0 & W
\end{array}\right]
$$

Where $I_{n}$ is a $\mathrm{n} \times$ n-dimensional identity matrix $Q, S$ and $W$ are positive definite matrices ${ }^{11}$. The coefficients of the contemporaneous relations among variables are assumed to evolve independently in each equation, although it is not a crucial assumption, yet it simplifies the inference and increases the efficiency of the estimation algorithm.

\subsection{Bayesian Estimation}

Estimation of model is carried out using the Bayesian approach which will be employed for evaluation of posterior distribution of the parameters of interest, in specific to our case $B^{T} A^{T} \Sigma^{T}$ and the hyperparameters of the variance covariance matix $V$. The Bayesian approach is feasible in a scenario where the distinction between parameters and shocks is less clear while one is dealing with unobservable components ${ }^{12}$. Nevertheless, in this study, Gibbs Sampling is employed for the posterior numerical evaluation of the parameters of interest. To start with, 48 observations (three years period) are chosen for a training sample. Thereafter, 10000 iterations of Gibbs Sampling will be chosen with a burn rate of $20 \%$ i.e. 2000 iterations (so that the effect of initial values on the posterior inference is minimized.) Gibbs Sampling is a particular variant of the Markov Chain Monte Carlo (MCMC) methods that consists of drawing from lower dimensional conditional posteriors as opposed to the high dimensional joint posterior of the whole parameter set. Considering that the MCMC is a smoothing method and hence delivers smoothed estimates, i.e. estimates of the parameters of interest based on the entire available set of data. Specifically, in a study like this where the objective is an investigation of the true evolution of the unobservable states over time, the smoothed estimates are more efficient and hence preferable (See Primiceri, 2005 for detailed discussion) ${ }^{13}$. Nevertheless,

\footnotetext{
${ }^{11}$ A point to note here is that none of the restrictions on the structure of $\mathrm{V}$ are essential as all the zero blocks could be substituted by non-zero blocks, with only small modifications of the estimation procedure. Nevertheless, there are at least two reasons suggesting a choice of $\mathrm{V}$ as the one described in the equation (8). The first one is related to the already high number of parameters of the model. Adding all the off diagonal elements of $\mathrm{V}$ would require the specification of a sensible prior, able to prevent cases of ill-determined parameters. The second reason is that allowing for a completely generic correlation structure among different sources of uncertainty would preclude any structural interpretation of the innovations.

12 In addition to that, there are three reasons to choose and prefer Bayesian over the Classical estimation approach to estimate subject class models. Firstly, if the variance of the time varying coefficients is small, the classical maximum likelihood estimator of this variance has a point mass at zero, related to the commonly called pile-up problem ${ }^{12}$.Secondly, classical maximum likelihood is related to the high dimensionality and nonlinearity of the problem which is a problem as such a complicated model often has a likelihood with multiple peaks, some of which is uninteresting or implausible regions of the parameter space. Moreover, if these peaks are very narrow, the likelihood may reach particularly high values, not at all representative of the model's fit on a wider and more interesting parameter region. In a Bayesian setting, the use of uninformative priors on reasonable regions of the parameter space is nevertheless effective in ruling out these misbehaviours. Lastly, the practicality of approach, writing up of the likelihood of the model is possible (at least in principle) yet, it is a hard task to maximize it over such a high dimensional space. Bayesian methods deal efficiently with the high dimension of the parameter space and the nonlinearities of the model, splitting the original estimation problem into smaller and simpler ones. Concomitantly, Bayesian seems the appropriate approach to consider.

${ }^{13}$ The Strategy of considering the whole sample and then discrete break has an innovative aspect and will give us further insight into the under analysis relationship in two different ways.
} 
filtered estimates in the subject study are also not very appropriate because they would exhibit transient variation even in time invariant models as pointed out by Sims (2001).

\subsection{Prior selection}

The selection of prior distributions is based on their appropriateness and applicability. To start with, the assumption that the initial states for the coefficients, for the covariances, for the log volatilities and the hyperparameters are independent of each other is intuitive. The priors for the hyperparameters, $Q, W$ and the blocks of $\mathrm{S}$, are assumed to be distributed as independent inverseWishart. The priors for the initial states of the time varying coefficients, simultaneous relations and $\log$ standard errors $p\left(B_{0}\right), p\left(a_{0}\right)$, and $p\left(\log _{\sigma 0}\right)$, are assumed to be normally distributed. These assumptions together with (5), (6) and (7) imply normal priors on the entire sequences of the B's, $\alpha$ 's and $\log \sigma$ 's (conditional on Q, W and S). The use of normal priors is fairly standard and also not being conjugate they have advantages in terms of tractability (See, Smith and Kohn 2002, Sims and Zha 1998, and Primiceri, 2005). As mentioned earlier, the MCMC algorithm is used to generate a sample from the joint posterior of $B^{T} A^{T} \Sigma^{T}$ and $V$. Gibbs sampling is used in order to exploit the blocking structure of the unknowns and it is performed in four steps, i) drawing in turn time varying coefficients $B^{T}$, ii) simultaneous relations $A^{T}$, iii) volatilities $\Sigma^{T}$ and iv) hyperparameters $V$, conditional on the observed data and the rest of the parameters ${ }^{14}$. This empirical framework layout is applied to the data. The details of the dataset are as follows: -

\subsection{Dataset}

The data set includes the series on the three variables of interest which are real exchange rate, inflation and trade balance, the details of each are as follows:

Inflation: For inflation, we used the Consumer Price Index (CPI) which is also the official target of the Bank of England monetary policy. Hence, the most suitable proxy in this context.

Exchange Rate: For exchange rate, the Real Effective Exchange Rate (REER) index is used, as it is the weighted average of the exchange rate of Sterling against the major trade partner's currencies.

Balance of Payment: The current account balance as a percentage of GDP was used as the proxy, the data available was quarterly observations which were converted into monthly observations by linear interpolation.

The data set includes the monthly observations from January 1989 to September $2016(\mathrm{~N}=336)$. The data on inflation and the current account balance was obtained from the Office for National Statistics (ONS) while on the REER data was obtained from the Bank of England's Bankstats.

\section{Analysis and Findings}

The REER are ordered last, it is due to the exogenous nature of exchange rate shocks. Moreover, the identification assumption also employs exchange rate shocks affects with lags. The simultaneous interaction between REER, CPI and BoP is arbitrarily modelled in a lower triangular form with the $\mathrm{BoP}$ first. It is not an identification condition but for the sake of normalisation, although the arbitrary normalisation may have the potential to make a difference, however, in this setting the ordering of the REER block did not affect the results. We chose 10000 iterations of Gibbs Sampling with a burn rate of $20 \%$ i.e. (2000 iterations). The 48 observations (three years) period was chosen for a training sample. To start with, it is important to have a look at the time varying standard deviation of the REER shocks. Figure 2 presents the plot of the posterior mean and the $16^{\text {th }}$ and $84^{\text {th }}$ percentiles of the

\footnotetext{
${ }^{14}$ For details on identification and structural interpretation, please see Primiceri (2005).
} 
time varying standard deviation of the REER shocks. The percentiles correspond to the bound of a one standard deviation confidence interval.
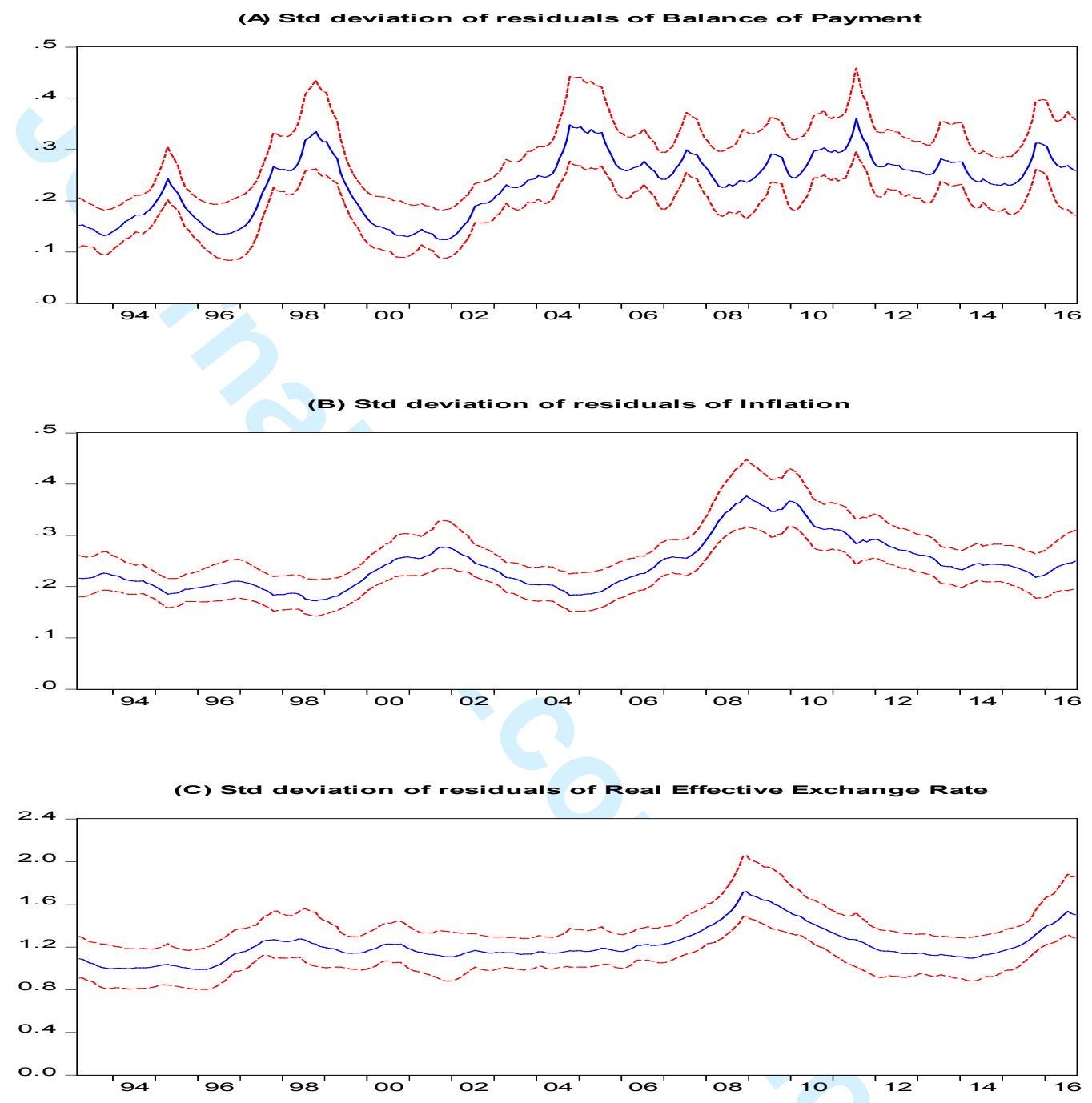

Figure 2: Posterior mean, $16^{\text {th }}$ and 84-th percentiles of the standard deviation of (A) residual of the Balance of Payment(Trade) as \% GDP (B) residual of the Inflation Rate and (C) residuals of the equation for Real Effective Exchange Rate Shocks

Figure 2 (A to C) presented above gives some interesting insight into the behaviour of under analysis series, the balance of trade has been persistently volatile while inflation has been rather smooth in the pre and post GFC periods. It is also obvious that the GFC exchange rates did show higher variance which is understandable in terms of financial turmoil and high volatility. Thereafter we can witness a consistent oscillation and rather smoothing pattern which again increased in volatility as we approached the period of the Brexit saga and associated volatility.

The dynamics of the REER shocks and response of the trade balance are summarised in the following Figure 3 (A-E). It presents the impulse responses of the trade balance to the REER shocks in four different dates of the under analysis sample. It also presents the pairwise difference between impulse responses in different dates with the 16-th and 84-th percentiles. The dates chosen for the comparison are August 2007, December 2013, June 2016 and December 2016. The choice of dates is due to the corresponding macro financial events and environment of prevailing periods. August 2008 is just 
before the $\mathrm{GFC}^{15}$. December 2013 corresponds to the period when the UK ran its largest trade deficit (6\% of GDP) since record began in 1956. June 2016 is the month of the Brexit referendum and December is the latest data available post-Brexit.

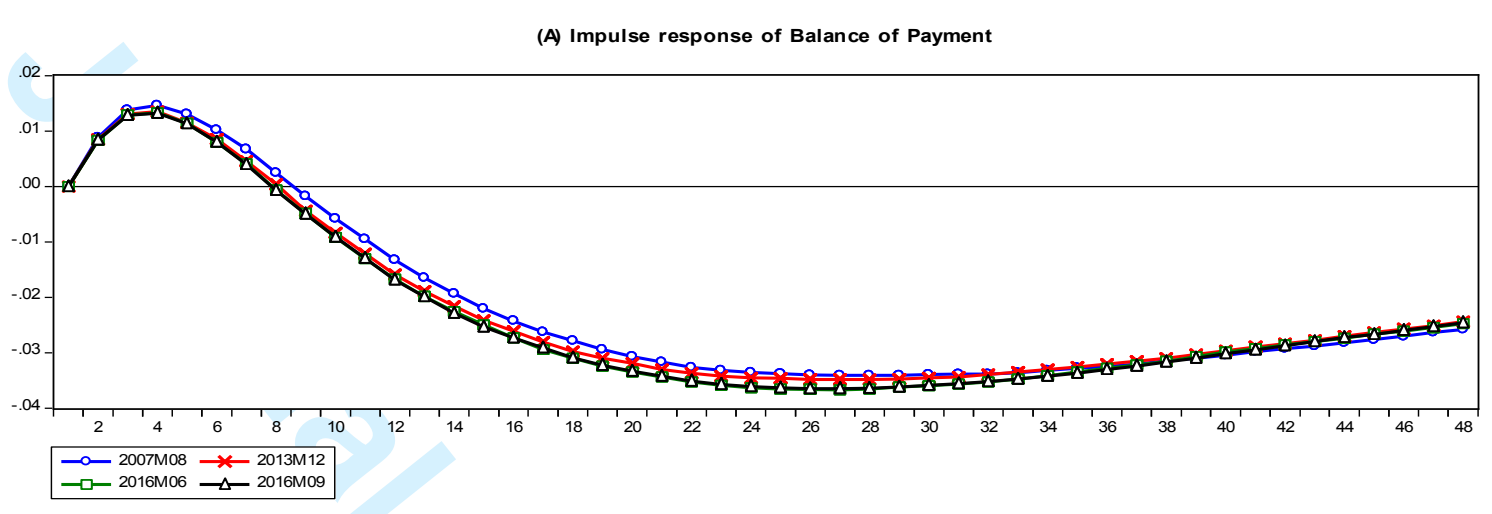

(B) Impulse response of BoP 2007M08

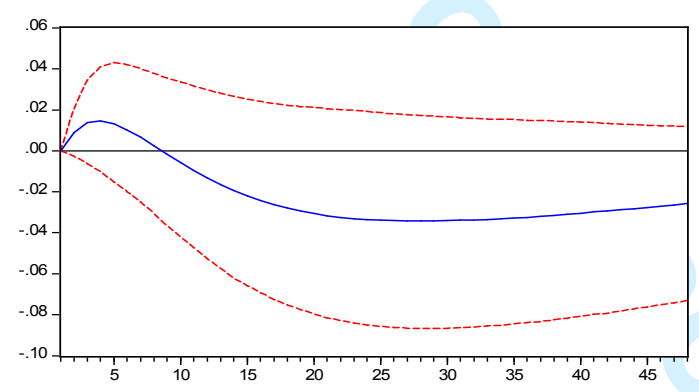

(D) Impulse response of BoP $2016 \mathrm{m06}$

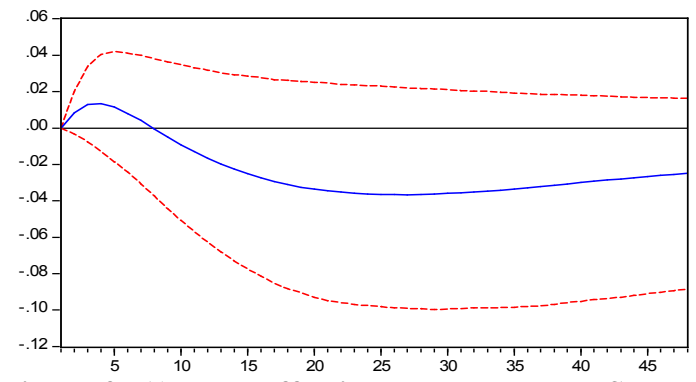

(C) Impulse response of BoP 2013M12

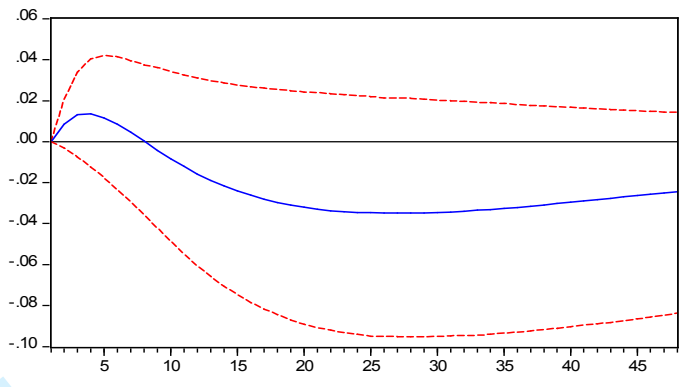

(E) Impulse response of BoP $2016 \mathrm{~m} 09$

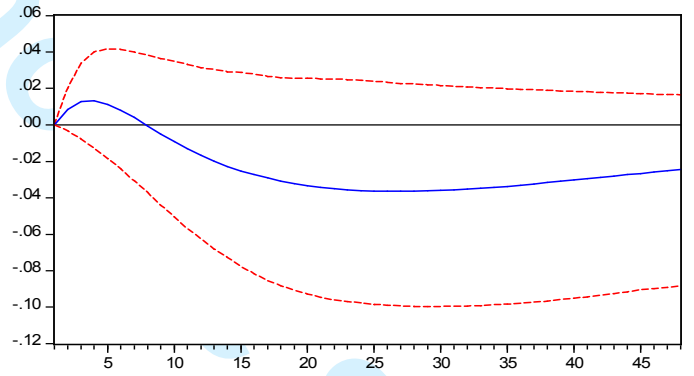

Figure 3: A) Real Effective Exchange Rate Shocks August 2007, Dec 2013, June and September 2016 (B E) Pairwise difference between the responses in corresponding periods with 16-th and 84-th percentiles.

The results show the shock to the real effective exchange rate (appreciation), after an initial improvement there was a persistent worsening of the current account. This suggests a J-curve behaviour $^{16}$ (although in the opposite direction due to positive shocks) and implies that the depreciation of the currency in the real sense does bring international competitiveness for the UK economy and external balance. On this aspect, the findings are in line with, studies for instance on USA \& Indonesia by Bahmani-Oskooee and Harvey (2015) and among others, Bahmani-Oskooee and Ratha (2004), Bahmani-Oskooee and Hegerty (2010) and Bahmani-Oskooee et al., (2013), Yildirim and Ivrendi (2016). The findings are contrary to the Aristotelous (2001) analysis (limited to UK-US trade) and Rose and Yellen (1989) on the US data and Rose (1991) analysing the Post-Breton Woods

15 Just before the Northern-Rock, secured help from the British Government to over-come liquidity crises.

16 The J-curve is the notion that describes a countries trade balance following a depreciation/devaluation of currency. The trade balance initially worsens before brining longer-term positive effects (for detailed discussion see Bahmani-Oskooee and Ratha (2004). 
period (1974 - 86) of five OECD (UK, Canada, US, Germany, Japan). Perhaps, this is prima facie evidence of the changes in the relationship between exchange rates and trade balance as economic integration and openness has increased over time. These findings also compliment and add to the work by Bahmani-Oskooee and Kovyryalova (2008) and Pattichis (2012) which were focusing on US-UK trade and a recent study by Bahmani-Oskooee (2016) which was focusing on the UK and its trading partners (Germany, US, Canada, Italy, Japan, Korea, Spain and Norway). There is strong evidence of J-curve behaviour which implies that the sharp depreciation can contribute to overcoming the adverse outlook of UK historical trade balance. Nonetheless, there were subtle differences in the periods Pre and Post-Global Financial Crises, which indicates that the relationship has grown stronger which could be associated with the increase in integration of economies as well as non-recessionary and crises periods in the global economy where the exchange rate depreciations can be more helpful. The pairwise difference (3B-3E) did not show much difference in the association in different periods which is an indication of the robustness of the relationship in the face of time variations.

The shock to the REER and the responses of inflation and the pairwise differences are presented in the Figure $4(A-E)$.

(A) Impulse response of Inflation

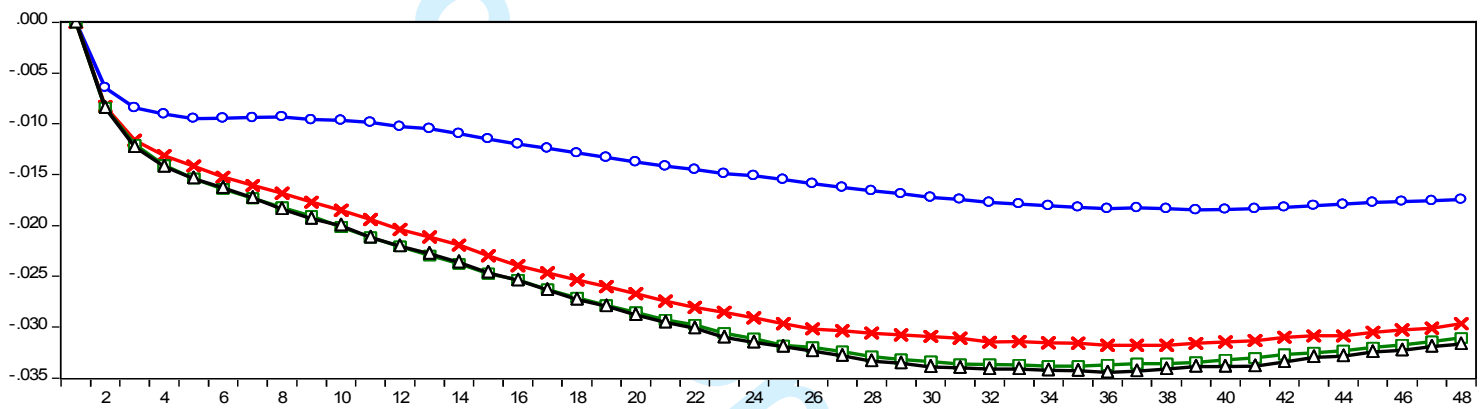

$\longrightarrow$ - 2007M08 $\rightarrow-2013 \mathrm{M} 12$ $\longrightarrow$ - 2016M06 $\triangle \longrightarrow 2016 \mathrm{M} 09$

(B) Impulse response of Inflation 2007M08

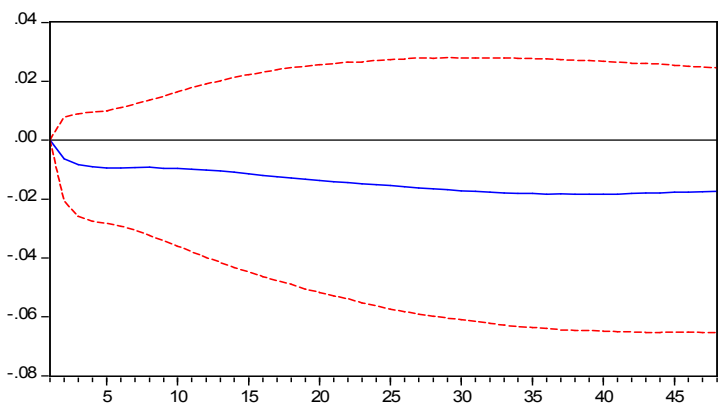

(C) Impulse response of Inflation 2013M12
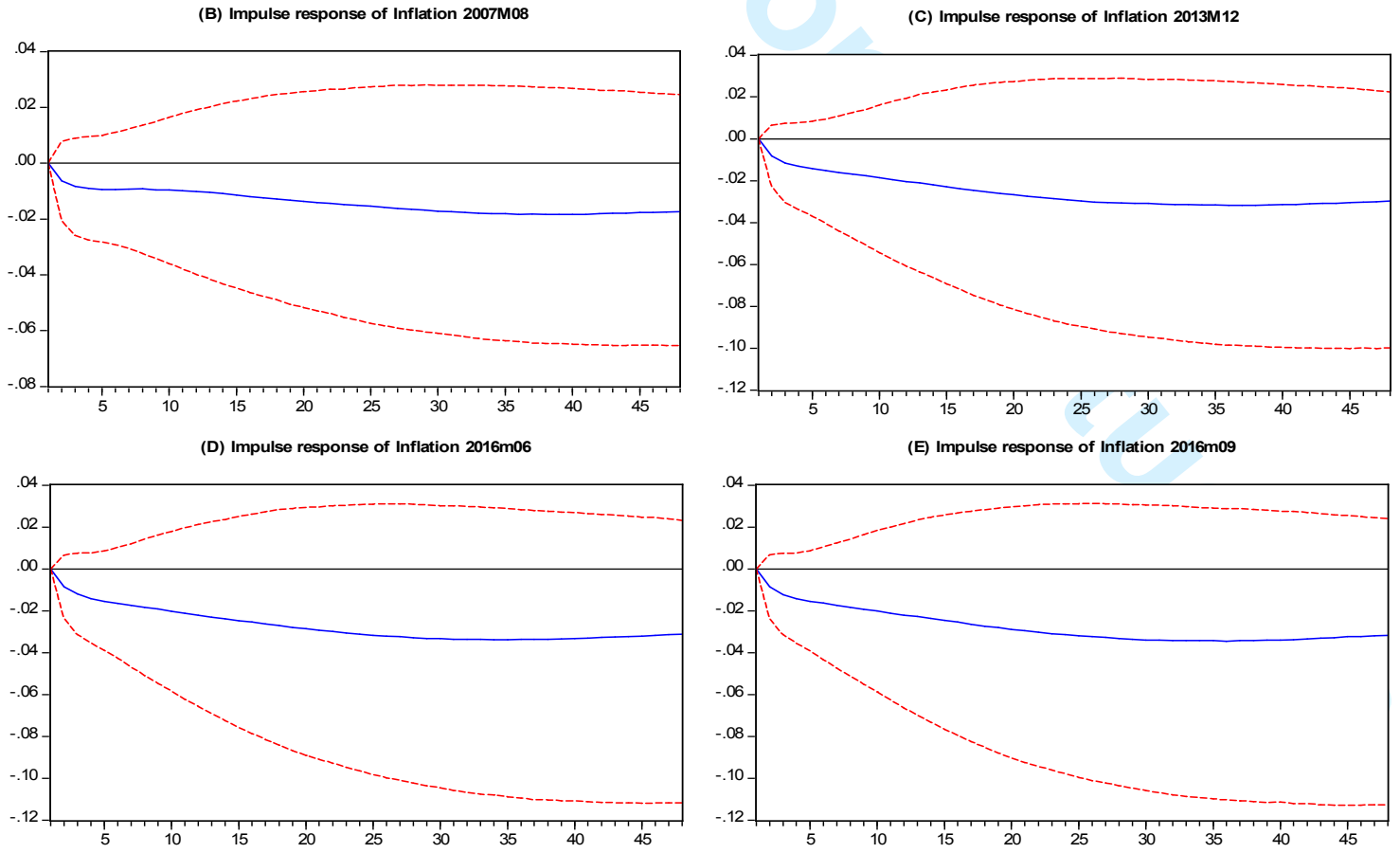

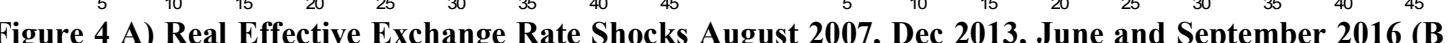
E) Pairwise difference between the responses in corresponding periods with 16-th and 84-th percentiles. 
The positive shock to the Real Effective Exchange Rate (appreciation) led to a persistent negative response from inflation. This implies a drop in the inflation rate due to the appreciation of GBP in real terms, putting this differently, depreciation leads to an increase in the inflation rate. The findings complement the studies, for instance, Bahmani-Oskooee (1991) which was focusing on less developed countries. Nonetheless, it adds to existing knowledge and provides an alternative perspective to the argument by Pourroy (2012) that a managed exchange rate environment delivers a stronger nominal anchor to inflation shock and concomitantly helps in inflation targeting, in specific to the UK the exchange rate is not managed but inflation has a statutory target, hence the depreciation has implications for price stability. Furthermore, the findings are also contrary to the Calvo and Reinhart (2000) argument that the pass through of inflation from exchange rate swings is larger in the emerging markets as compared to developed countries, it also contradicts the notion by Gagnon and Ihrig (2004) and Edwards (2007) that the countries that have adopted inflation targeting have experienced a decline in the pass-through from exchange rate changes to inflation. Perhaps, it is prima facie evident that for the UK where we have an explicit and statutory inflation-targeting framework the deprecation has sustainable implications for inflation. Hence, to say least, the 25 years of inflation targeting in the UK may or may not have some success in taming inflation, however, our findings suggests that the nexus between inflation and exchange rate (Pass-through) holds its grounds fairly strongly. Nonetheless, it is also obvious that in comparison to the Pre-Global Financial Crisis, the response of inflation was rather more pronounced which implies that exchange rate has become more effective for inflation dynamics. In fact, the recent and Post-Brexit period showed a greater impact on inflation which indicates that the Pass-through has been increasing over time. Furthermore, the increase in the pass through over times also indicates the difference between the recessionary periods around the Global Financial Crisis and the recent period when the economy has been growing. The pairwise difference did not show significant results implying the robustness of association in the face of time-variation. It leads us to conclude in the next section.

\section{Conclusion:}

On the basis of our empirical framework, we can hereby conclude that the exchange rate has significant implications for the UK's external balance and price stability. Depreciation has a silver lining as it could lead to an increase in international competitiveness and rebalancing of the balance of trade deficit as well as a steering inflation to its target. The study also has wider economic implication beyond Brexit, as it implied that the J-curve behaviour of the trade balance holds. Nonetheless, it is also implied that the strategy of inflation targeting which has been adopted by some of the central banks including the Bank of England has not diminished the effects of depreciation on inflation (Pass-through). However, we would acknowledge that these findings and implications should be taken with a pinch of salt as the future holds a lot of uncertainty around Brexit and future trading arrangements. Perhaps, these findings also have very important policy implication in terms of future trading relations between the UK and the European Union. A Soft-Brexit where the trade channels and trading arrangements are to a large extent analogous to the ones that prevailed during the EU membership may occasion the fruits of depreciation discussed in this treatise with higher probabilities of occurrence.

\section{Reference}

Aftab, M. Syed, K.B.S. Katper, N.A (2017)," Exchange-rate volatility and Malaysian-Thai bilateral industry trade flows ", Journal of Economic Studies, Volume 44 (1) pages 99 - 114. 
Ali, S.Z. Anwar, S. (2016), Can exchange rate pass-through explain the price puzzle? Economics Letters 145, pages 56-59.

Aristotelous, K. (2001), Exchange-rate volatility, exchange-rate regime, and trade volume: evidence from the UK-US export function (1889-1999), Economics Letters 72, pages 87-94.

Bahmani-Oskooee, M. (1991), Effects of exchange rate variability on inflation variability, World Development, Volume 19 (6), pages 729-733

Bahmani-Oskooee, M. (1991), Is there a long-run relation between the trade balance and the real effective exchange rate of LDCs? Economics Letters 36, pages 403- 407.

Bahmani-Oskooee, M. Ratha, A. (2004), “The J-curve: a literature review”, Applied Economics, Volume 36 (13), pages 1377-1398.

Bahmani-Oskooee, M. Kovyryalova, M. (2008), "The J-curve: evidence from industry trade data between the US and UK”, Economic Issues, Volume 13 (1), pages 25-44.

Bahmani-Oskooee, M. Hegerty, S.W. (2010), "The J- and S-curves: a survey of the recent literature", Journal of Economic Studies, Volume 37 (6), pages 580-596.

Bahmani-Oskooee, M., Harvey, H. Hegerty, S.W. (2013), "Empirical tests of the Marshall-Lerner condition: a literature review", Journal of Economic Studies, Volume 40 (3), pages 411-443.

Bahmani-Oskooee, M. Halicioglu, F. Ghodsi, S. H (2016), Asymmetric Effects of Exchange Rate Changes on British Bilateral Trade Balances, 18th Annual Conference of ETSG, Helsinki-Finland, September 8-10, 2016

Balcilar, M. Gupta, R. Jooste, C. (2016)," The dynamic response of the rand real exchange rate to fundamental shocks ", Journal of Economic Studies, Volume 43 (1) pages 108 - 121.

Boyd, D., Caporale, G.M. Smith, R. (2001), "Real exchange rate effects on the balance of trade: cointegration and the Marshall-Lerner condition", International Journal of Finance \& Economics, Volume 6 (3), pages 187-200.

Calvo, G.A. Reinhart, C.M. (2000), "Fixing for your life”, NBER Working Paper, 8006.

Canarella, G. Miller, S.M. (2016)," Inflation persistence and structural breaks The experience of inflation targeting countries and the USA ", Journal of Economic Studies, Vol. 43 Iss 6 pp. 980 - 1005

Gerlach, S. (1994), On the symmetry between inflation and exchange rate targets, Economics Letters 44, pages $133-137$

Pattichis, C. (2012),"Exchange rate effects on trade in services", Journal of Economic Studies, Volume 39 (6), pages $697-708$.

Chiu, Y-B., Lee, C-C. Sun, C-H. (2010), "The US trade imbalance and real exchange rate: an application of the heterogeneous panel cointegration method", Economic Modelling, Volume 27 (3), pages $705-716$.

Cogley, T. (2003), "How Fast Can the New Economy Grow? A Bayesian Analysis of the Evolution of Trend Growth", University of California, Davis, mimeo.

Cogley, T. Sargent. T.J. (2003), "Drifts and Volatilities: Monetary Policies and Outcomes in the Post WWII U.S.”, New York University, mimeo.

Edwards, S. (2006), The Relationship Between Exchange Rates and Inflation Targeting Revisited, NBER Working Paper No. 12163 
Forbes, K. (2015), Much ado about something important: How do exchange rate movements affect inflation? 47th Money, Macro and Finance Research Group Annual Conference, Cardiff

Gagnon, J.E. Ihrig. J. (2004), "Monetary Policy and Exchange Rate Pass-Through.” International Journal of Finance and Economics, Volume 9(4), pages 315-338.

GFCI (2016), The Global Financial Centres Index 20 available at [http://www.longfinance.net/images/gfci/20/GFCI20_26Sep2016.pdf] accessed $9^{\text {th }}$ January 2016.

Ghosh, A.R. Qureshi, M.S. Tsangarides, C. G. (2013), Is the exchange rate regime really irrelevant for external adjustment? Economics Letters 118, pages 104-109.

Haldane, A. G. (1995). Targeting Inflation: A Conference of Central Banks on the Use of Inflation Targets Organised by the Bank of England, 9-10 March 1995. London: Bank of England.

Hume, D. (1742), Essays, Moral, Political, and Literary, Edinburgh: A. Kincaid.

Keynes, J.M. (1938), J. M. Keynes to R. F. Harrod , 4 July 1938, CWK XIV: 296-7.

Lane, P.R. Milesi-Ferretti, G. M (2002), External wealth, the trade balance, and the real exchange rate, European Economic Review, Volume 46, pages 1049 - 1071.

Mishkin, F.S. (1998), "The dangers of exchange rate pegging in emerging-market countries", International Finance, Volume 1, pages 81-101.

Office for National Statistics (2016), Statistical Bulletins: UK Trade January 2016.

Primiceri, G. E (2005), Time Varying Structural Vector Auto-regression and Monetary Policy, Review of Economic Studies, 72, Pages 8214-852.

Pourroy, M. (2012), Does exchange rate control improve inflation targeting in emerging economies? Economics Letters, 116, Page 448-450

Rizki E. Wimanda , (2014)," Threshold effects of exchange rate depreciation and money growth on inflation Evidence from Indonesia ", Journal of Economic Studies, Volume 41 (2), pages196 - 215.

Rose, A.K. Yellen, J.L. (1989), “Is there a J-curve?”, Journal of Monetary Economics, Volume 24 (1), pages 53-68.

Rose, A. K (1990), Exchange rates Some evidence from and the trade balance developing countries, Economic Letters, 34, pages 172-275.

Rose, A. K (1991), The role of exchange rates in a popular model of international trade: Does the 'Marshall-Lerner' condition hold? Journal of International Economics, Volume 30 (3-4), Pages 301316

Sims C. A. (2001), “Comment on Sargent and Cogley's: 'Evolving Post World War II U.S. Inflation Dynamics"', NBER Macroeconomics Annual, MIT Press, Cambridge, Massachusetts, Page 373-379.

Sims C. A. T. ZHA (1998), "Bayesian Methods for Dynamics Multivariate Models", International Economic Review, 39, pages 949-968.

Smith, M. R. Kohn (2002), "Parsimonious Covariance Matrix Estimation for Longitudinal Data", Journal of the American Statistical Association, 97, Pages 1141-1153.

Yildirim, Z. Ivrendi, M. (2016)," Exchange rate fluctuations and macroeconomic performance Evidence from four fast-growing emerging economies ", Journal of Economic Studies, Volume 43(5), 


$$
\text { pages } 678-698 \text {. }
$$

